\title{
Influence of hydrotherapy on clinical and cardiac autonomic function in migraine patients
}

\author{
M. U. Sujan, M. Raghavendra Rao², Ravikiran Kisan, Hulegar A. Abhishekh, Atchayaram Nalini¹, Trichur R. Raju, \\ T. N. Sathyaprabha \\ Departments of Neurophysiology and ${ }^{1}$ Neurology, National Institute of Mental Health and Neurosciences, ${ }^{2}$ Department of Complementary and \\ Alternative Medicine, Health Care Global Enterprises Private Ltd., Bengaluru, Karnataka, India
}

\begin{abstract}
Background: Migraine is associated with autonomic symptoms. The growing body of literature suggests that the dysfunctional autonomic nervous system might play a pivotal role in the pathogenesis of migraine. Thermal therapies have been hypothesized to modulate these changes and alleviate pain. However, data regarding the efficacy of hydrotherapy in migraine remain scant. We evaluated the effect of add on hydrotherapy procedure (a hot arm and foot bath with ice massage to head) in migraine patients. Methods: Forty chronic migraine patients fulfilling the International Classification of Headache Disorders II criteria were recruited from the neurology outpatient clinic. Patients were randomized to receive either hydrotherapy plus conventional pharmacological care $(n=20)$ or conventional medication only $(n=20)$. Hydrotherapy group received treatment with hot arm and foot bath $\left(103^{\circ} \mathrm{F}\right.$ to $110^{\circ} \mathrm{F}$ ) and ice massage to head daily for $20 \mathrm{~min}$ for 45 days. Patients were assessed using headache impact test (HIT), visual analog scale for pain and cardiac autonomic function by heart rate variability (HRV) before and after intervention period. Results: There was a significant decrease in HIT score, frequency, and intensity of headaches following treatment in both the groups. However, it was more evident in add on hydrotherapy group compared to pharmacological treatment alone group. There was also significant improvement in the HRV parameters. In particular, there was a significant decrease in heart rate $(P=0.017)$, increase in high frequency $(\mathrm{HF})(P=0.014)$ and decrease in low frequency/HF ratio $(P=0.004)$ in add on hydrotherapy group. Conclusion: Our study shows that add on hydrotherapy enhanced the vagal tone in addition to reducing the frequency and intensity of headaches in migraine patients.
\end{abstract}

Key words: Headache, heart rate variability, hydrotherapy, migraine

\section{Introduction}

Migraine is a chronic debilitating disorder which is associated with significant morbidity. It is known to affect the productivity of work resulting in a substantial economic loss. Apart from this, migraine has a significant impact on quality of life of patients. ${ }^{[1-3]}$

The converging evidence from different experimental paradigm suggest that autonomic dysfunction may be the core aspect in the pathogenesis of migraine. The studies

\begin{tabular}{|l|l|}
\hline \multicolumn{2}{|c|}{ Access this article online } \\
\hline Quick Response Code: & Website: \\
\hline & www.ruralneuropractice.com \\
\hline & \\
\hline
\end{tabular}

have shown an increased cardiac dysfunction and cardiovascular disease risk in migraineurs compared to nonmigraineurs. ${ }^{[4-7]}$ Abnormal activity of hypothalamic region as demonstrated by imaging studies might affect the autonomic activity. ${ }^{[8,9]}$ In particular, chronic sympathetic dysfunction may play a key role in the pathogenesis of this disorder. ${ }^{[10]}$

Although pharmacological interventions reduce the symptoms of migraine, a substantial number of patients does not improve with the medications. ${ }^{[11]}$ Several complementary and alternative medicine approaches such as relaxation training, biofeedback, and yoga are known to significantly reduce frequency and severity of migraine..$^{[12-15]}$

Hydrotherapy is one of the oldest nonpharmacological treatments. Hydrotherapy is reported to be useful in many diseases. In particular, patients with rheumatoid arthritis, osteoarthritis, fibromyalgia, and back pain are

\section{Address for correspondence:}

Dr. T. N. Sathyaprabha, National Institute of Mental Health and Neuro Sciences, Hosur Road, Bengaluru - 560 029, Karnataka, India.

E-mail: drsathyaprabha@gmail.com 
shown to improve with hydrotherapy. ${ }^{[16-20]}$ It is known to cause initial local vasoconstriction followed by reflexive vasodilatation. Vasogenic inflammation and constrictions are hallmarks of migraine. Though, controlled studies are not available it is plausible that hydrotherapy may be useful in migraine patients. We designed this study to evaluate the efficiency of hydrotherapy in the form of hot arm and foot bath with ice massage to head in migraine patients in comparison with conventional treatment. In addition, we assessed the cardiac autonomic function using heart rate variability (HRV) before and after the treatment.

\section{Methods}

Subjects were recruited through referrals from the outpatient department of neurology at National Institute of Mental Health and Neurosciences. They were asked to complete a diary regarding the headache frequency and intensity for 4 weeks. Following inclusion criteria were observed: Individuals of either gender, age 18 and above, meeting the International Classification of Headache Disorders criteria for migraine with or without aura, a headache frequency of 5-15 per month and a history of at least 2 years of migraine. Patients with marked depression, anxiety or psychosis; more than two visits/month for mental health care, open skin wound, active dermatitis, major medical illness under treatment, pregnancy, clotting disorders, recent head or neck trauma within 2 years and presence of a cardiac pacemaker or other implanted or external electrical device were excluded.

Institutional Ethics Committee approved the study and written informed consent was obtained from all the participants. Those identified through the screening process as potentially eligible subjects were scheduled to meet with the study coordinator for the consenting process and undergo a baseline medical assessment including a complete medical history and physical examination. The study neurologist confirmed the diagnosis of migraine and excluded individual from the study with other medical problems that could put the patient at risk or confound the study results. Enrolled subjects were asked to avoid changes in medications, dietary supplements, and nonpharmacologic treatments for headache during the course of the study.

Eligible subjects were instructed to maintain a daily headache diary for 4 consecutive weeks while continuing usual care. After they had completed 4 weeks of diaries, their entries are reviewed with the study neurologist to determine eligibility for the treatment phase of the study. Eligibility consists of completion of at least $80 \%$ of headache diaries and report of at least 5 migraines. They were asked to continue their headache diaries for the full duration of the study.

Subjects were randomized to any one of the two treatment arms using a concealed allocation protocol. At the subject's first treatment visit, the study coordinator performed a brief intake interview and then opened an opaque, sequentially numbered envelope that identifies which treatment group has been randomly selected for the subject.

Of 40 patients, 20 patients were randomly allocated to receive hydrotherapy + conventional care (drug) for 45 days, and another 20 patients were allocated to conventional therapy only for 45 days. All patients were assessed before and after the treatment using HRV, headache impact test (HIT) questionnaire, and pain visual analog scale (VAS). Assessments were carried out at baseline after randomization and 6 weeks thereafter.

Headache specific quality of life was measured using HIT-6. The scale consists of 6 items which measures headache-related disability: Pain, social functioning, role functioning, vitality, cognitive functioning, and psychological distress. ${ }^{[21]}$ The headache frequency was determined from the daily headache diary. Headache intensity was assessed using VAS.

Autonomic function tests were carried out in the autonomic laboratory, Department of Neurophysiology, National Institute of Mental Health and Neurosciences under standardized conditions. Artifact free, lead II electrocardiogram (ECG) was recorded in all subjects. Signals were conveyed through the analog digital converter (Power Lab, 16 channels data acquisition system, AD Instruments, Australia). The sampling rate was $1024 \mathrm{~Hz}$. An error-free 5 min ECG segment was taken for analysis. Time and frequency domain parameters were computed according to the task force report on HRV. ${ }^{[22]}$ Time domain parameters such as standard deviation of RR intervals standard deviation of Normal to Normal interval (SDNN) in milliseconds, square root of the mean squared differences of successive intervals in milliseconds and frequency domain parameters such as low frequency (LF) spectral power in $\mathrm{ms}^{2}$, high frequency (HF) spectral power in $\mathrm{ms}^{2}$ also in HF normalized units (HF.nu), LF normalized units (LF.nu), and LF and HF ratio (LF/HF) were estimated using customized software. ${ }^{[23-25]}$

Hydrotherapy procedure was as follows. Subjects were required to drink a glass of tepid water and sit in an arm and foot bath (Nature Life Company, Bengaluru) by 
immersing arms in arm bath and legs in foot bath tub. The temperature of the bath was maintained between $103^{\circ} \mathrm{F}$ and $110^{\circ} \mathrm{F}$. A blanket was enveloped around the person and bath to prevent cool air from contact with skin and prevent dissipation of heat from the bath. Simultaneously, ice massage was given to the head and scalp using the ice bag for $5 \mathrm{~min}$. The head was then thoroughly rubbed dry with a cloth while the subject continued to immerse his hands and feet in warm water. The duration of this arm and foot bath was for $20 \mathrm{~min}$. On coming out of the bath, the arm and foot were rubbed dry using dry cloth. This intervention was given 5 days a week for 6 weeks.

The conventional care group received Nonsteroidal anti-inflammatory drugs (domperidone $10 \mathrm{mg}$, naproxen sodium $500 \mathrm{mg}$ [NAXDOM]) (if needed) and prophylactic medication Flunarizine (Sibelium) - $10 \mathrm{mg} 1$ tablet daily for 6 weeks.

\section{Data analysis}

Data were found to deviate significantly from a normal distribution. Square root transformation of HRV variables was done. Nonparametric inferential statistics was used. Data were analyzed using Mann-Whitney test for between the groups and Wilcoxon test to analyze within group effects in the study. $P<0.05$ is considered statistically significant.

\section{Results}

The mean age of the study population was $32.6 \pm 2.3$ years; and mean duration of illness was $13 \pm 2.9$ years. There was a significant decrease in HIT score in add on hydrotherapy group compared pharmacotherapy alone group $(Z=-4.894$ and $P \leq 0.000)$. Withingroup, Wilcoxontest showed significant decrease in HIT score in hydrotherapy group $(Z=-3.937, P \leq 0.000)$, similar observation was noted in other group too $(Z=-3.846, P \leq 0.000)$. There was a significant decrease in frequency of headache after intervention in hydrotherapy group compared to conventional care group $(Z=-4.285$ and $P \leq 0.000)$. A significant decrease in intensity of headache was noted in hydrotherapy group compared to conventional group $(Z=-5.488, P \leq 0.000)$ [Table 1$]$.

There was a significant decrease in heart rate $(Z=-2.380, P=0.017)$ following intervention in hydrotherapy group compared to pharmacotherapy alone group. There was a significant increase in HF which indicates an increase in parasympathetic activity in add on hydrotherapy group $(Z=-2.435, P=0.014)$. There was also a significant decrease in LF/HF ratio a measure of sympathovagal balance in add on hydrotherapy group compared to pharmacotherapy alone group $(Z=-2.867, P=0.004)$. Wilcoxon test showed a significant decrease in heart rate $(Z=-2.501, P=0.012)$, LF power $(Z=-2.501, P=0.012)$, $\mathrm{LF} / \mathrm{HF}$ ratio $(Z=-3.285, P=0.001)$ in add on hydrotherapy group after the treatment. However, there was no significant difference in heart rate, $\mathrm{HF}$ power, and $\mathrm{LF} / \mathrm{HF}$ ratio in conventional care group [Table 2].

\section{Discussion}

The results from this study demonstrate that add on hydrotherapy in migraine patients improves quality of life, decreases frequency and intensity of headache after 6 weeks of treatment. To our knowledge, this is the first study which investigated effects of hydrotherapy in migraine patients.

Previous investigations have demonstrated an abnormality of HRV in migraine. ${ }^{[7,26,27]}$ Recent studies reported the beneficial influence of yoga and acupuncture on HRV in patients with migraine. ${ }^{[14,28]}$ Our study shows similar autonomic modulatory influence of hydrotherapy.

Mechanism by which hydrotherapy brings positive effects remains speculative. Sensory stimuli of hydrotherapy

Table 1: Data of HIT score, intensity and frequency of pain in pre- and post-treatment ( $n=20$ in each group)

\begin{tabular}{|c|c|c|c|}
\hline & Pretreatment & Posttreatment & Difference in the scores \\
\hline \multicolumn{4}{|l|}{ HIT score } \\
\hline Hydrotherapy+pharmacotherapy group & $75.95 \pm 4.94$ & $41.70 \pm 6.49^{* * *}$ & $34.25 \pm 6.74$ \\
\hline Pharmacotherapy alone group & $75.20 \pm 5.44$ & $65.75 \pm 14.15^{\star \star *}$ & $9.45 \pm 1.42^{+++}$ \\
\hline \multicolumn{4}{|l|}{ Intensity of pain } \\
\hline Hydrotherapy+pharmacotherapy group & $8.95 \pm 0.60$ & $2.10 \pm 0.85^{\star \star \star}$ & $6.85 \pm 0.67$ \\
\hline Pharmacotherapy alone group & $9.55 \pm 1.79$ & $7.50 \pm 1.27^{\star * *}$ & $2.05 \pm 1.35^{+++}$ \\
\hline \multicolumn{4}{|l|}{ Frequency of pain } \\
\hline Hydrotherapy+pharmacotherapy group & $10.65 \pm 5.14$ & $2.00 \pm 0.97^{\star * *}$ & $8.65 \pm 4.35$ \\
\hline Pharmacotherapy alone group & $10.25 \pm 3.16$ & $7.10 \pm 1.88^{\star \star \star}$ & $3.15 \pm 1.98^{+++}$ \\
\hline
\end{tabular}

Data presented in mean \pm SD. ${ }^{*} P<0.05,{ }^{\star *} P<0.01,{ }^{\star \star \star} P<0.001$ for within groups Wilcoxon's test and ${ }^{+} P<0.05,{ }^{++} P<0.01,{ }^{+++} P<0.001$ for between groups MannWhitney test. SD: Standard deviation, HIT: Headache impact test 
Sujan, et al:: Migraine and hydrotherapy

Table 2: HRV parameters before and after treatment ( $n=20$ in each group)

\begin{tabular}{|c|c|c|c|}
\hline & Pretreatment & Posttreatment & $\begin{array}{c}\text { Difference between } \\
\text { pre- and post-treatment } \\
\text { values }\end{array}$ \\
\hline \multicolumn{4}{|l|}{ Heart rate (beats per min) } \\
\hline Hydrotherapy+pharmacotherapy group & $76.2 \pm 11.3$ & $70.3 \pm 11.2^{*}$ & $5.9 \pm 10.2$ \\
\hline Pharmacotherapy alone group & $72.6 \pm 10.2$ & $75.0 \pm 11.5$ & $-2.42 \pm 11.9^{+}$ \\
\hline \multicolumn{4}{|l|}{ SDNN in ms } \\
\hline Hydrotherapy+pharmacotherapy group & $6.10 \pm 1.65$ & $6.10 \pm 1.32$ & $0.018 \pm 1.45$ \\
\hline Pharmacotherapy alone group & $8.02 \pm 4.93$ & $7.52 \pm 2.66$ & $0.50 \pm 3.09$ \\
\hline \multicolumn{4}{|l|}{ RMSSD in ms } \\
\hline Hydrotherapy+pharmacotherapy group & $5.19 \pm 1.68$ & $5.69 \pm 1.82$ & $-0.50 \pm 1.50$ \\
\hline Pharmacotherapy alone group & $6.72 \pm 3.15$ & $6.51 \pm 2.40$ & $0.21 \pm 1.82$ \\
\hline \multicolumn{4}{|l|}{ Total power (TF) in $\mathrm{ms}^{2}$} \\
\hline Hydrotherapy+pharmacotherapy group & $40.18 \pm 23.04$ & $37.53 \pm 16.56$ & $2.66 \pm 21.71$ \\
\hline Pharmacotherapy alone group & $84.52 \pm 162.86$ & $60.76 \pm 52.69$ & $23.78 \pm 116.68$ \\
\hline \multicolumn{4}{|l|}{ Low-frequency power (LF) in $\mathrm{ms}^{2}$} \\
\hline Hydrotherapy+pharmacotherapy group & $7.98 \pm 3.58$ & $7.01 \pm 2.81^{*}$ & $0.97 \pm 2.37$ \\
\hline Pharmacotherapy alone group & $11.80 \pm 22.16$ & $9.17 \pm 11.99^{*}$ & $2.62 \pm 10.24^{+}$ \\
\hline \multicolumn{4}{|l|}{ High frequency power (HF) in $\mathrm{ms}^{2}$} \\
\hline Hydrotherapy+pharmacotherapy group & $7.19 \pm 3.43$ & $8.47 \pm 4.30^{*}$ & $-1.28 \pm 3.66^{+}$ \\
\hline Pharmacotherapy alone group & $8.24 \pm 7.39$ & $7.44 \pm 3.72$ & $0.80 \pm 3.92$ \\
\hline \multicolumn{4}{|l|}{ Low frequency/high frequency (LF/HF) } \\
\hline Hydrotherapy+pharmacotherapy group & $1.16 \pm 0.34$ & $0.89 \pm 0.31^{\star \star}$ & $0.27 \pm 0.29$ \\
\hline Pharmacotherapy alone group & $1.20 \pm 0.57$ & $1.11 \pm 0.53$ & $0.090 \pm 0.21^{++}$ \\
\hline
\end{tabular}

Data presented in square root transformed mean \pm SD. ${ }^{*} P<0.05,{ }^{* *} P<0.01,{ }^{* * *} P<0.001$ for within groups Wilcoxon's test and ${ }^{+} P<0.05,{ }^{+} P<0.01,{ }^{+++} P<0.001$ for between groups Mann-Whitney test. SD: Standard deviation, HRV: Heart rate variability, SDNN: SD of NN interval, RMSSD: Root mean square of the successive differences, TF: Total frequency, LF: Low frequency, HF: High frequency

may dominate the painful stimuli by activation of large diameter myelinated fibers. This may lead to loss of gate to small nociceptive impulses. Both hypo and hyperthermia are known to exert strong physiological and hemodynamic effects on the body. ${ }^{[18]}$ Studies have shown that warm water exposure decreases sympathetic power and increase vagal tone. ${ }^{[29,30]}$ It is plausible that vasogenic inflammation and constriction that are hallmarks of migraine may be modulated by thermal applications resulting in clinical improvement.

One of the major limitations of the study was that the patients were not on daily analgesic medication and were required to take medication only on a need basis. Only prophylactic medication was taken daily for the period of 45 days. The variability in medication intake could have partly confounded the results though medication intake was significantly more in pharmacotherapy alone group compared to hydrotherapy group. Conversely, hydrotherapy interventions could have helped patients need for medication. Future studies should compare this intervention with standard nonpharmacologic control arms such as relaxation and biofeedback that has been shown in a meta-analysis to reduce headache symptoms.

The findings from this study show benefit of hydrotherapy in reducing headache symptoms and improving quality of life. Further studies with larger sample size are needed to confirm these findings.

\section{References}

1. D’Amico D, Grazzi L, Usai S, Leonardi M, Raggi A. Disability and quality of life in headache: Where we are now and where we are heading. Neurol Sci 2013;34 Suppl 1:S1-5.

2. Pryse-Phillips W, Findlay H, Tugwell P, Edmeads J, Murray TJ, Nelson RF. A Canadian population survey on the clinical, epidemiologic and societal impact of migraine and tension-type headache. Can J Neurol Sci 1992;19:333-9.

3. Steiner TJ, Scher AI, Stewart WF, Kolodner K, Liberman J, Lipton RB. The prevalence and disability burden of adult migraine in England and their relationships to age, gender and ethnicity. Cephalalgia 2003;23:519-27.

4. Avnon Y, Nitzan M, Sprecher E, Rogowski Z, Yarnitsky D. Different patterns of parasympathetic activation in uni- and bilateral migraineurs. Brain 2003;126:1660-70.

5. Bugdayci G, Yildiz S, Altunrende B, Yildiz N, Alkoy S. Salivary alpha amylase activity in migraine patients. Auton Neurosci 2010;155:121-4.

6. Ekici B, Unal-Cevik I, Akgul-Ercan E, Morkavuk G, Yakut Y, Erkan AF. Duration of migraine is associated with cardiac diastolic dysfunction. Pain Med 2013;14:988-93.

7. Nilsen KB, Tronvik E, Sand T, Gravdahl GB, Stovner LJ. Increased baroreflex sensitivity and heart rate variability in migraine patients. Acta Neurol Scand 2009;120:418-23.

8. Alstadhaug KB. Migraine and the hypothalamus. Cephalalgia 2009;29:809-17.

9. Leone M, Proietti Cecchini A, Mea E, Curone M, Tullo V, Casucci G, et al. Functional neuroimaging and headache pathophysiology: New findings and new prospects. Neurol Sci 2007;28 Suppl 2:S108-13.

10. Peroutka SJ. Migraine: A chronic sympathetic nervous system disorder. Headache 2004;44:53-64.

11. Law S, Derry S, Moore RA. Sumatriptan plus naproxen for acute migraine 
attacks in adults. Cochrane Database Syst Rev 2013;10:CD008541.

12. Büssing A, Ostermann T, Lüdtke R, Michalsen A. Effects of yoga interventions on pain and pain-associated disability: A meta-analysis. J Pain 2012;13:1-9.

13. John PJ, Sharma N, Sharma CM, Kankane A. Effectiveness of yoga therapy in the treatment of migraine without aura: A randomized controlled trial. Headache 2007;47:654-61.

14. Kisan R, Sujan M, Adoor M, Rao R, Nalini A, Kutty BM, et al. Effect of Yoga on migraine: A comprehensive study using clinical profile and cardiac autonomic functions. Int J Yoga 2014;7:126-32.

15. Waller B, Lambeck J, Daly D. Therapeutic aquatic exercise in the treatment of low back pain: A systematic review. Clin Rehabil 2009;23:3-14.

16. Bender T, Karagülle Z, Bálint GP, Gutenbrunner C, Bálint PV, Sukenik S. Hydrotherapy, balneotherapy, and spa treatment in pain management. Rheumatol Int 2005;25:220-4.

17. Langhorst J, Musial F, Klose P, Häuser W. Efficacy of hydrotherapy in fibromyalgia syndrome - A meta-analysis of randomized controlled clinical trials. Rheumatology (Oxford) 2009;48:1155-9.

18. Mooventhan A, Nivethitha L. Scientific evidence-based effects of hydrotherapy on various systems of the body. N Am J Med Sci 2014;6:199-209.

19. Mortimer R, Privopoulos M, Kumar S. The effectiveness of hydrotherapy in the treatment of social and behavioral aspects of children with autism spectrum disorders: A systematic review. J Multidiscip Healthc 2014;7:93-104.

20. Plecash AR, Leavitt BR. Aquatherapy for neurodegenerative disorders. J Huntingtons Dis 2014;3:5-11.

21. Yang M, Rendas-Baum R, Varon SF, Kosinski M. Validation of the Headache Impact Test $\left(\mathrm{HIT}^{\mathrm{T}} \mathrm{6}^{\mathrm{TM}}\right)$ across episodic and chronic migraine. Cephalalgia 2011;31:357-67.

22. Heart rate variability: Standards of measurement, physiological interpretation and clinical use. Task Force of the European Society of Cardiology and the North American Society of Pacing and Electrophysiology. Circulation 1996;93:1043-65.
23. Abhishekh HA, Kumar NC, Thirthalli J, Chandrashekar H, Gangadhar BN, Sathyaprabha TN. Prolonged reaction to mental arithmetic stress in first-degree relatives of schizophrenia patients. Clin Schizophr Relat Psychoses 2014;8:137-42.

24. Abhishekh HA, Nisarga P, Kisan R, Meghana A, Chandran S, Trichur R, et al. Influence of age and gender on autonomic regulation of heart. J Clin Monit Comput 2013;27:259-64.

25. Dhargave P, Nalini A, Abhishekh HA, Meghana A, Nagarathna R, Raju TR, et al. Assessment of cardiac autonomic function in patients with Duchenne muscular dystrophy using short term heart rate variability measures. Eur J Paediatr Neurol 2014;18:317-20.

26. Gass JJ, Glaros AG. Autonomic dysregulation in headache patients. Appl Psychophysiol Biofeedback 2013;38:257-63.

27. Perciaccante A, Fiorentini A, Valente R, Granata M, Tubani L. Migraine and heart rate variability. Arch Intern Med 2007;167:2264.

28. Bäcker M, Grossman P, Schneider J, Michalsen A, Knoblauch N, Tan L, et al. Acupuncture in migraine: Investigation of autonomic effects. Clin J Pain 2008;24:106-15.

29. Perini R, Veicsteinas A. Heart rate variability and autonomic activity at rest and during exercise in various physiological conditions. Eur J Appl Physiol 2003;90:317-25.

30. Nishimura M, Onodera S. Effects of water temperature on cardiac autonomic nervous system modulation during supine floating. J Gravit Physiol 2001;8:P65-6.

How to cite this article: Sujan MU, Rao MR, Kisan R, Abhishekh HA, Nalini A, Raju TR, et al. Influence of hydrotherapy on clinical and cardiac autonomic function in migraine patients. J Neurosci Rural Pract 2016;7:109-13.

Source of Support: Central Council for Research in Yoga and Naturopathy, Department of AYUSH, Ministry of Health and Family Welfare, Government of India, New Delhi. Conflict of Interest: None declared. 